\title{
Ninjurin1 Is Up-regulated in Circulating Prostate Tumor Cells and Plays a Critical Role in Prostate Cancer Cell Motility
}

\author{
JURI PARK ${ }^{1 *}$, JAE-YOUNG JOUNG $^{1 *}$, JI-EUN HWANG ${ }^{1}$, DONGWAN HONG ${ }^{2}$, \\ WEON SEO PARK ${ }^{3}$, SANG-JIN LEE ${ }^{1}$ and KANG HYUN LEE ${ }^{1}$ \\ ${ }^{1}$ Genitourinary Cancer Branch, ${ }^{2}$ Cancer Immunology Branch, ${ }^{3}$ Hematologic Malignancy Branch, \\ Research Institute of National Cancer Center, Goyang, Republic of Korea
}

\begin{abstract}
Background/Aim: Ninjurinl is a 17-kDa membrane protein that is highly expressed in circulating tumor cells (CTCs) obtained from locally-advanced prostate cancer patients. As CTCs are implicated in the initiation of distant metastasis, we examined the potential contribution of Ninjurin1 to the motility of prostate cancer cells. Materials and Methods: Ninjurin1 expression was evaluated in CTCs harvested from seven locally advanced patients with no metastatic hallmarks using real-time polymerase chain reaction $(P C R)$. The role of Ninjurin1 in cell motility was investigated using small interfering RNA (siRNA), neutralizing antibodies against Ninjurin1 and Ninjurin1overexpressing adenoviruses. Results: Ninjurin1 was ranked as the most significantly up-regulated adhesion protein identified by RNA-Seq analysis. Both Ninjurin1 downregulation by siRNA and neutralizing antibodies blocking Ninjurin1 homophilic interactions effectively inhibited cell motility. In contrast, cell motility was enhanced in prostate cancer cells infected with adenovirus enabling Ninjurin1 overexpression. Conclusion: Ninjurin1-neutralizing antibodies or Ninjurinl-targeting siRNA merit further development for patients with metastatic potential.
\end{abstract}

Prostate cancer is the second most common cancer among males in Western countries (1). The disease progresses from high-grade prostate intra-epithelial neoplasia to locally invasive carcinoma and, ultimately, to metastatic cancer, the

*These Authors contributed equally to this study.

Correspondence to: Sang-Jin Lee, Research Institute National Cancer Center, Goyang, Gyeonggi-do 410-769, Republic of Korea. Tel: +82 319202455, Fax: +82 31920542, e-mail: leesj@ncc.re.kr and Kang-Hyun Lee, Research Institute National Cancer Center, Goyang, Gyeonggi-do 410-769, Republic of Korea. Tel: +82 319202455, Fax: +82 31920542, e-mail: uronco@ncc.re.kr

Key Words: Prostate cancer, Ninjurin1, circulating tumor cell, invasion, migration. latter of which is associated with a high mortality rate. Metastases to the bone, lymph nodes, liver and lung account for more than $10 \%$ of cancer-related deaths in men. Patients with prostate cancer have a relatively favorable 5-year survival rate, partly due to early detection and effective androgen deprivation therapy. However, a significant number of prostate cancer patients become resistant to this type of treatment. Patients who develop androgen-independent and metastatic prostate cancer have few therapeutic options, with the 5-year survival rate, associated with these patients, being as low as $12.6 \%$. Therefore, it is imperative to investigate the mechanisms underlying prostate cancer metastasis to facilitate the discovery of novel therapeutic targets and treatment approaches. As circulating tumor cells (CTCs) include precursors that are able to colonize distant metastatic sites, they are likely to provide insight into the genomic features associated with metastatic tumor cells.

Capturing sufficient amounts of the extremely limited number of CTCs in the blood, required for sequencing, is an enormous challenge. To date, the most effective strategy for purifying CTCs is based on the utilization of membrane surface proteins expressed on CTCs (2). Using a microfluidic capture platform coated with EpiCAM-reactive antibodies, several studies have been able to obtain CTCs and analyze their genetic profile. Allele-specific polymerase chain reaction (PCR) amplification, array comparative genomic hybridization (CGH) and next-generation sequencing, as well as whole-genome amplification have revealed somatic single nucleotide variants and copy number variations associated with prostate cancer (3-5). Furthermore, single molecule RNA sequencing has demonstrated that the wingless-related integration site (WNT) pathway is critical to the suppression of anoikis and to the enhancement of anchorage-independent sphere formation and metastatic potential (2). Analyzing genomic mutations in CTCs using established methods for cell enrichment and isolation, genomic amplification, library qualification and census-based sequencing has become a standard protocol for evaluating prostate cancer (6). We developed an alternative approach in which a replication- 
competent adenovirus is introduced exclusively into prostatespecific antigen/prostate-specific membrane antigen (PSA/PSMA)(+) cells, with this method not being dependent on EpiCAM or specific membrane proteins (7). Interestingly, this approach enabled us to detect circulating prostate cancer cells from several patients who had not been clinically diagnosed with metastatic tumor nodules. In addition, RNASeq analyses demonstrated that several metastasis-associated genes were up-regulated in these patients and Ninjurin1 was top-ranked among most significantly changing adhesion molecules.

Ninjurin1 (nerve injury-induced protein 1), a 17-kDa homophilic molecule that localizes to the cell membrane, is strongly induced by nerve injury in dorsal root ganglion neurons and Schwann cells (8). Thus, the myeloid cells of patients with experimental allergic encephalomyelitis or active multiple scleroses express high levels of Ninjurin1, a phenomenon that facilitates the infiltration of inflammatory myeloid cells into the central nervous system (9). Another study reported that Ninjurin1 is up-regulated in highly migratory $\mathrm{T}$ cells in the lungs of an experimental autoimmune encephalomyelitis (EAE) rat model and plays an important role in invading central nervous system vessels (10). In addition to its association with nervous system pathologies, Ninjurin 1 is over-expressed in multiple cancers, including hepatocellular carcinoma (11), acute lymphoblastic B-cell leukemia (12) and high-grade bladder cancer (13). Furthermore, we observed enhanced Ninjurin1 expression in docetaxel-resistant prostate cancer cells. As little is known regarding the metastatic-related function of Ninjurin 1 in cancer cells, we investigated how it would contribute to motility of CTCs during prostate cancer progression.

\section{Materials and Methods}

Cells. The human prostate cancer cell lines PC3 and DU145 (ATCC, Manassas, VA, USA) were maintained in RPMI 1640 supplemented with 10\% FBS and 1\% penicillin/streptomycin (Invitrogen, Carlsbad, CA, USA). Docetaxel-resistant prostate cancer cells were established by prolonged exposure to $5 \mathrm{nM}$ docetaxel. CTCs were maintained in Dulbecco's high glucose MEM supplemented with $10 \%(\mathrm{v} / \mathrm{v})$ FBS and $1 \%(\mathrm{v} / \mathrm{v})$ antibiotics.

Counting CTCs in prostate cancer blood using Ad5/35E1aPSESE4. For the separation of peripheral blood mononuclear cells (PBMCs) from whole blood, $5 \mathrm{ml}$ of whole blood in a K2 EDTA tube was added to a $50 \mathrm{ml}$ conical tube containing $4 \mathrm{ml}$ of Ficoll-Paque PLUS (GE Healthcare Life Science, Pittsburg, PA, USA) and was gently mixed with PBS to reach a total volume of $10 \mathrm{ml}$. The PBMC sample was prepared in a 12 -well plate as described (7). Then, PBMCs were infected with 0.01 multiplicity of infection (MOI) of Ad5/35E1aPSESE4 and determined whether to contain CTCs mediating green fluorescent protein (GFP) expression. Tumor cells were maintained in Dulbecco's High Glucose MEM medium supplemented with $10 \%(\mathrm{v} / \mathrm{v})$ FBS and $1 \%(\mathrm{v} / \mathrm{v})$ antibiotics.
RNA-Seq analysis. The control and test RNA, libraries were constructed using the SENSE mRNA-Seq Library Prep Kit (Lexogen, Inc., Vienna, Austria) following the manufacturer's instructions with minor modifications. Briefly, $2 \mu \mathrm{g}$ of total RNA from each sample was incubated with magnetic beads coated with oligo(dT) and all other RNA except for mRNA was removed with washing solution. The library was generated by randomly hybridizing starter/stopper heterodimers to poly(A) RNA bound to the magnetic beads. The starter/stopper heterodimers contained Illumina-compatible linker sequences. Reverse transcription and ligation reactions in a single tube extended the starter to the next hybridized heterodimer and the newly-synthesized cDNA insert was then ligated to the stopper. Second strand synthesis was performed to release the library from the beads and the library was subsequently amplified. Barcodes were introduced during the amplification of the library. High-throughput sequencing was performed with paired-end 100 sequencing using the HiSeq 2000 platform (Illumina, Inc., Sang Diego, CA, USA). RNASeq reads were mapped using the TopHat software tool (http://bioinformatics.oxfordjournals.org/content/25/9/1105.abstract) to generate the alignment file. The alignment file was used to assemble the transcripts, estimate the levels of each transcript and identify differentially expressed genes or isoforms using Cufflinks. To identify novel targets of prostate cancer in CTCs, we carried out a robust cluster analysis and statistically analyzed the association between the RNA-Seq data from 2 CTC samples and the publically available RNA-Seq data from 3 prostate normal tissue samples. First, 153 genes associated with cell adhesion function were classified using the AmiGO database (14). We selected 56 genes with a $\geq 2$-fold change in expression and $\geq 2$ standard deviations between the CTC and normal tissue samples. Student's $t$-test was used to evaluate differentially expressed genes with a cut-off $p$-value $<0.05$.

PCR and real-time PCR analysis. Total RNA was extracted using TRIzol reagent (Invitrogen), according to the manufacturer's protocols. cDNA was synthesized from the extracted RNA in a total reaction volume of $20 \mu \mathrm{l}$ containing $10 \mathrm{mM}$ Tris- $\mathrm{HCl},(\mathrm{pH} \mathrm{8.8)}, 50$ $\mathrm{mM} \mathrm{KCl}, 5 \mathrm{mM} \mathrm{MgCl}{ }_{2}, 1 \mathrm{mM}$ each dNTP, $0.5 \mu \mathrm{g}$ oligo(dT) primers, $25 \mathrm{U}$ RNase inhibitor and $15 \mathrm{U}$ reverse transcriptase (Invitrogen) for $30 \mathrm{~min}$ at $42^{\circ} \mathrm{C}$ and, then, for $5 \mathrm{~min}$ at $95^{\circ} \mathrm{C}$. The following primers were used in the PCR reactions: Ninjurin 1 in cancer cells (5'-TGA GGG CCG TAG ACC TTG TA-3' and 5'-TAG AAA AGT GGG TGC TGG GA-3'), Ninjurin1 in CTC (5'-TGG TCC TCA TCT CCA TCT CC-3' and 5'-CAT GTC CAT CAA GGG CTT CT-3'), GAPDH (5'-TGG TCA CCA GGG CTG CTT TTA-3' and 5'-TCC TGG AAG ATG GTG ATG GGA -3') and HPRT1 (5'AGA CTT TGC TTT CCT TGG TCA G-3' and 5'-TCA AGG GCA TAT CCT ACA ACA A-3'). The PCR reaction was conducted using the following conditions: a 10 -min preheating step at $95^{\circ} \mathrm{C}, 30$ cycles of $30 \mathrm{~s}$ at $95^{\circ} \mathrm{C}, 3 \mathrm{~s}$ at $60^{\circ} \mathrm{C}$ and $30 \mathrm{~s}$ at $72^{\circ} \mathrm{C}$, and $10 \mathrm{~min}$ at $72^{\circ} \mathrm{C}$. For real-time PCR analysis, the same primers probed with fluorescence were added to each reaction mixture and the reactions were conducted using a real-time PCR instrument (Roche, Indianapolis, IN, USA).

Invasion assay. Cells $\left(1 \times 10^{4}\right.$ cells per well) were seeded into the $96-$ well plate provided with the Oris ${ }^{\mathrm{TM}}$ Cell Invasion Assay Kit (Platypus, Madison, WI, USA). The plate was incubated for $48 \mathrm{~h}$ at $37^{\circ} \mathrm{C}$ and the stoppers were then removed. Collagen I overlay was added to the wells to create a 3-D extracellular matrix (ECM) environment for invasion and the cells were, then, incubated for $1 \mathrm{~h}$ 
at $37^{\circ} \mathrm{C}$. After cell culture medium was added, the cells were allowed to invade for $72 \mathrm{~h}$. The membranes were stained with 4',6diamidino-2-phenylindole (DAPI) before images were captured. The sequences of the sense and antisense strands of the small interfering RNAs (siRNAs) targeting Ninjurin1 are as follows: Ninjurin1 siRNA (sense 5'-GUG UUC AUC AUC GUG GUA G-3' and antisense 5'C UAC CAC GAU GAU GAA CAC-3'). The AccuTarget ${ }^{\mathrm{TM}}$ Negative Control siRNA (Bioneer, Daejeon, South Korea) was used as a negative control. siRNA was custom synthesized and the negative control siRNA was purchased from Bioneer (Daejeon, Republic of Korea). For the siRNA experiments, $2 \times 105$ cells were seeded in each $60-\mathrm{mm}$ culture dish. Once cells had grown to $70 \%$ confluence, a mixture of $30 \mu \mathrm{l}$ of siRNA (20 pmoles/ $\mu \mathrm{l})$ and $30 \mu \mathrm{l}$ of Lipofectamine 2000 reagent (Invitrogen) was added to the medium of each dish. After $48 \mathrm{~h}$, cells were harvested for the invasion and migration assays.

Western blot. For the Western blot analyses, cells were lysed in radioimmunoprecipitation assay (RIPA) buffer supplemented with protease inhibitors (Sigma-Aldrich, St. Lois, MO, USA). Proteins $(20-50 \mu \mathrm{g})$ were resolved by sodium dodecyl sulfate-polyacrylamide gel electrophoresis (SDS-PAGE) and transferred to a polyvinylidene difluoride (PVDF) membrane. The membrane was probed with primary antibodies against Ninjurin1 (Cell Signaling, Danvers, MA, USA) and $\beta$-actin (Sigma-Aldrich) and, subsequently, probed with secondary antibodies (Jackson Immuno Research Laboratories, West Grove, MA, USA). Peroxidase-conjugated secondary antibodies were visualized using an Enhanced Chemiluminescence (ECL) Plus kit (Thermo Fisher Scientific, Waltham, MA, USA).

\section{Results}

The expression levels of adhesion molecules are enhanced in prostate CTCs. As previously reported (7), we developed a replication-competent adenovirus to fluorescently label CTCs derived from the blood of prostate cancer patients. As shown in Figure 1A-B, PSA/PSMA(+) prostate cancer cells in blood were labeled with fluorescence following infection with 0.01 MOI of Ad5/35E1aPSESE4. Subsequently, 39 leukocyte mixtures prepared from locally advanced prostate cancer patients were examined. Blood from prostate cancer patient at the metastatic stage was included as a positive control. Interestingly, ten patients, who had local tumors but had not been diagnosed with distant metastases, showed more than one CTC as summarized in Figure 1C. Epithelium-derived tumor cells initiate cancer progression and metastasis by undergoing a series of molecular events associated with cell adhesion, including the down-regulation of E-cadherin to reduce cell-cell adhesion and the upregulation of other cell adhesion molecules (CAMs). To identify the CAMs that play key roles during migration and invasion, we evaluated CTCs obtained from three patients using RNA-Seq analysis. As shown in Figure 2A, 56 of the 153 genes associated with cell adhesion function identified in the AmiGO database exhibited a $\geq 2$-fold change in expression with $\geq 2$ standard deviations between CTC samples and normal tissues. Ninjurin1 was the most significantly differentially expressed gene $(p=0.00426)$ according to hierarchical gene clustering, suggesting that it may play an important role in CTC motility in the blood. To confirm the up-regulation of Ninjurin 1 in CTCs from locally advanced prostate tumor, seven different CTCs were cultured and their total RNAs were tested for Ninjurin1 expression using real-time PCR. Six out of seven patients exhibited increased levels of Ninjurin 1 mRNA transcripts compared to normal prostate samples (Figure 2B). Since the presence of CTCs is indicative of potential distant metastases with poor survival rates (15), Ninjurin1 overexpression in CTCs suggests its critical role for cell motility.

Inhibiting Ninjurin1 expression or activity reduces cell motility in vitro. As Ninjurin 1 plays a critical role in the motility of immune cells, we evaluated cell invasion and migration in metastatic prostate cancer cells. To determine the role of Ninjurin1 in metastatic prostate cancer cell motility, we reduced Ninjurinl expression using siRNA. Ninjurin1 transcript levels were effectively reduced in PC3 (Figure 3A) and DU145 (Figure 3B) transfected with siRNA, as confirmed by RT-PCR. Forty eight hours following the transfection of $1 \times 10^{5}$ cells, they were incubated on a transwell membrane for $48 \mathrm{~h}$. As shown in Figure 3A-B, depletion of Ninjurinl transcripts led to reduced motility as assessed by invasiveness and migration assays. The migration ability of DU145 was reduced with no statistical significance. These results indicated that Ninjurin1 plays an important role in cell motility. Next, we evaluated cell invasion in cells treated with $500 \mathrm{ng} / \mathrm{ml}$ anti-Ninjurin1 antibodies to block Ninjurin1 activity. As shown in Figure 4, the neutralizing antibody effectively blocked cell invasion with statistical significance. Therefore, Ninjurin1 appears to be a motility-associated protein that is required for CTCs to enter the circulation.

Ninjurinl overexpression enhances cell motility in vitro. To evaluate the effects of Ninjurin1 overexpression, we analyzed cell migration and invasion in cells infected with an adenovirus expressing the Ninjurinl gene under the cytomegalovirus (CMV) promoter (Figure 5). In contrast with Ninjurin1 down-regulation, Ninjurin 1 overexpression strongly enhanced invasiveness and migration. These results further confirmed that Ninjurin1 plays a role in prostate cancer cell motility.

\section{Discussion}

Prostate cancer is a common cancer among men worldwide. Prostate cancer progression is dependent on signaling between androgens and androgen receptors; therefore, it is conventionally treated using androgen-deprivation therapy. However, most patients ultimately experience recurrent 

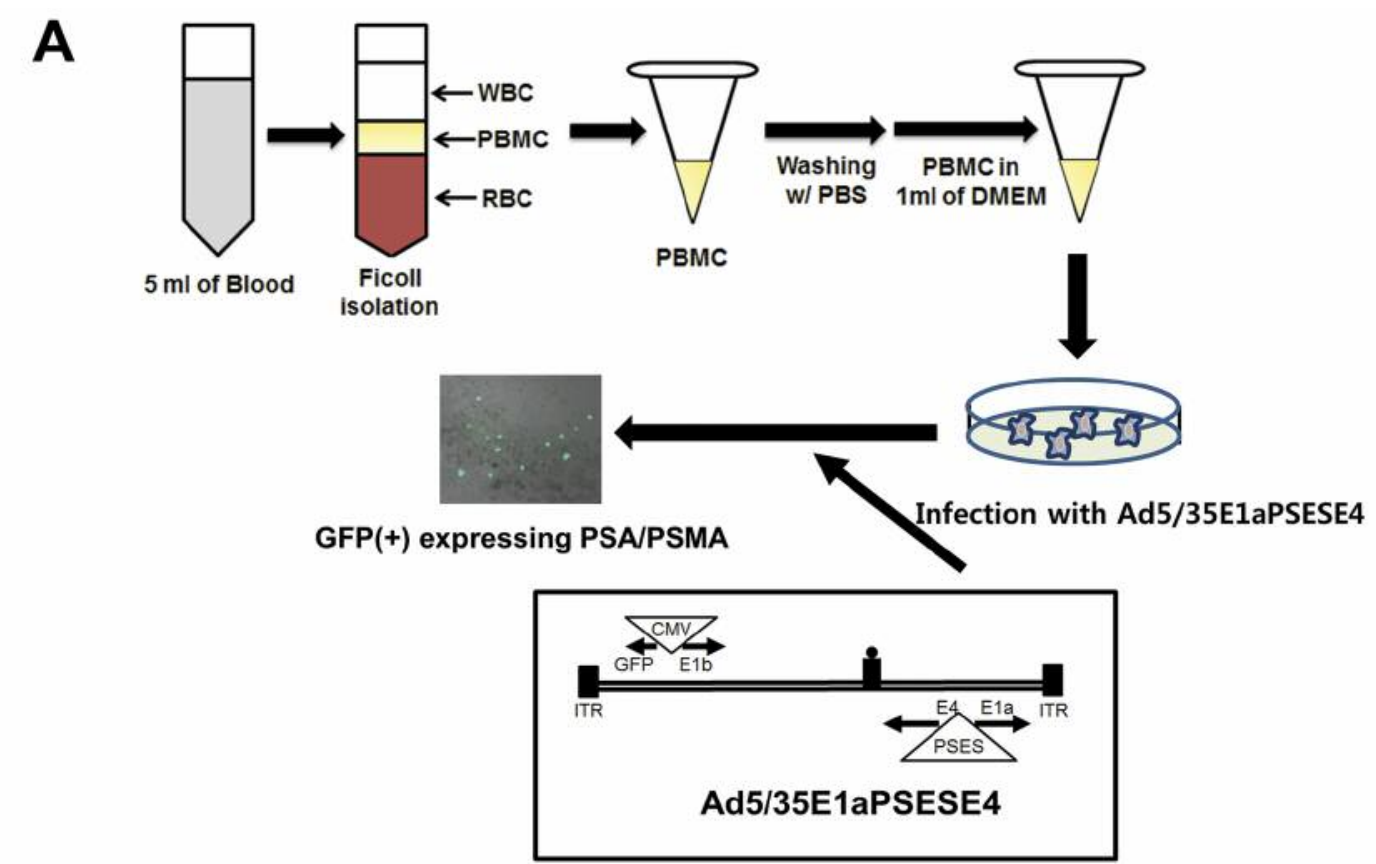

B

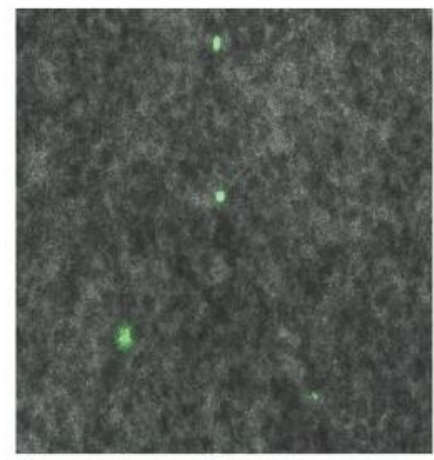

Patient \#1

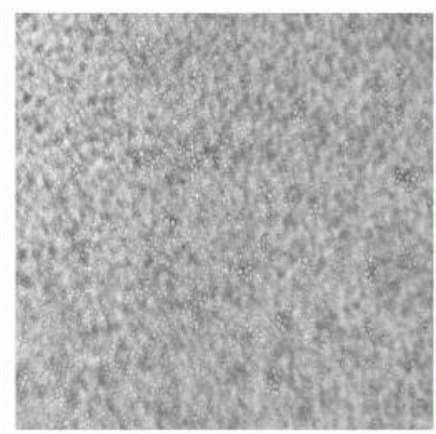

Negative control

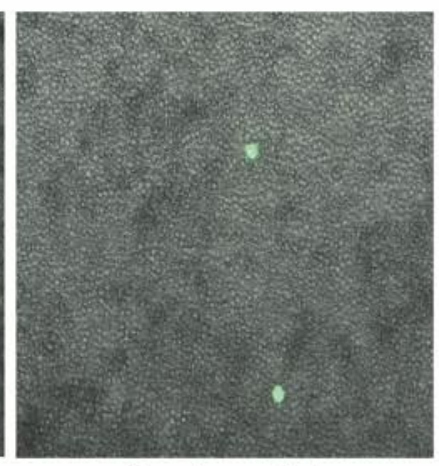

Patient \#1

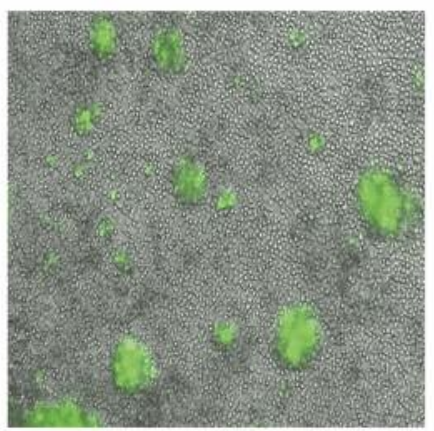

Bone-metastasized patient
C

\begin{tabular}{|c|c|c|}
\hline \multirow{2}{*}{ Tumor Stage } & $\begin{array}{c}\text { Number of } \\
\text { Detected CTC's }\end{array}$ & $\begin{array}{c}\text { Number of } \\
\text { Patients }\end{array}$ \\
\hline \multirow{2}{*}{$\begin{array}{c}\text { Locally Advanced } \\
\text { Prostate Cancer }\end{array}$} & 0 & 29 \\
\cline { 2 - 3 } & $1-5$ & 6 \\
\cline { 2 - 3 } & $\mathbf{5 - 1 0}$ & 3 \\
\hline \multirow{2}{*}{$\begin{array}{l}\text { Prostate Cancer } \\
\text { with metastasis }\end{array}$} & $>10$ & 1 \\
\hline
\end{tabular}

Figure 1. Circulating tumor cells (CTCs) from locally advanced prostate cancer patients were marked with replication-competent adenovirus. A: Peripheral blood mononuclear cells (PBMCs) obtained from Ficoll isolation of $5 \mathrm{ml}$ of blood were washed with PBS and re-suspended in $1 \mathrm{ml}$ of DMEM supplemented with 10\% FBS and 1\% antibiotics. PBMCs were infected with 0.01 M Ad5/35E1aPSESE4. B: Post 48 h infection, cells were observed under a fluorescence microscope. Blood from bone-metastasized was included as a positive control. C: PBMCs prepared from thirty nine patients who were diagnosed of locally advanced prostate cancer were tested for CTCs upon infection with Ad5/35E1aPSESE4. One prostate cancer from metastasis was included as a positive control. 
A

\begin{tabular}{|c|c|c|c|c|c|}
\hline $\begin{array}{c}\text { Patient } \\
\text { No. }\end{array}$ & Stage & PSA & PBMC & CTC & No. of CTC \\
\hline 1 & pT2aNX, GS6 & $<0.1$ & $2.78 \times 10^{6}$ & Yes & 3 \\
\hline 2 & pT2cNX, GS6 & $<0.1$ & $8.72 \times 10^{6}$ & Yes & 10 \\
\hline 3 & pT2cNX, GS7 & $<0.1$ & $1.8 \times 10^{6}$ & Yes & 2 \\
\hline
\end{tabular}

\begin{tabular}{|llll}
\hline Patient 1 & Patient 2 & Patient 3 & SRR057649 SRR057650 SRR057651
\end{tabular}

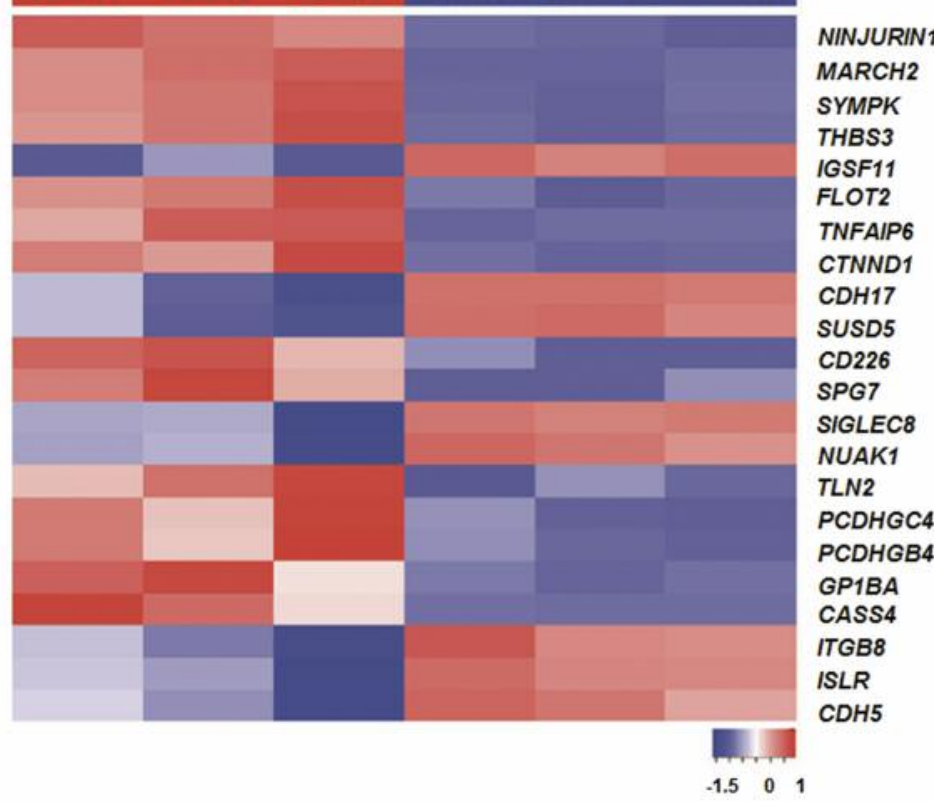

B

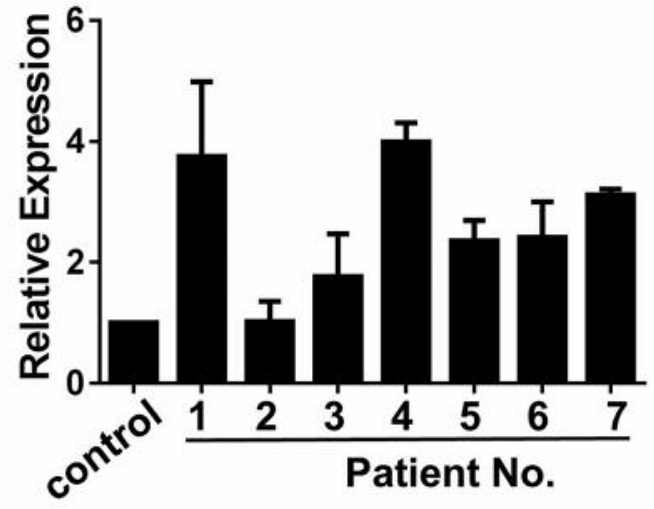

\begin{tabular}{|c|c|}
\hline Patient No. & $\begin{array}{r}\text { CTC No. } \\
\text { In } 5 \text { ml Blood }\end{array}$ \\
\hline 1 & 9 \\
\hline 2 & 1 \\
\hline 3 & 2 \\
\hline 4 & 2 \\
\hline 5 & 3 \\
\hline 6 & 7 \\
\hline 7 & 5 \\
\hline
\end{tabular}

Figure 2. Ninjurin1 is an adhesion protein that is highly expressed in prostate circulating tumor cells (CTCs). A. Cluster analysis of genes associated with cell adhesion. CTCs marked with fluorescence were grown for 2 weeks and subsequently lysed for RNA extraction with TRIzol. RNA-Seq analyses were then conducted as described in the Materials and Methods section. Gene expression levels determined by RNA-Seq were normalized using standard normalization techniques (mean $=0$ and standard deviation=1). Each row of the heat map is sorted in ascending order of $p$-values. $B$. The mRNA levels of the Ninjurin1 gene in normal prostate samples and 7 CTC samples harvested from the blood of patients with locally advanced prostate cancer were measured using real-time PCR. The relative amounts of transcripts after normalization with HPRT1 mRNA levels are shown. The mean values of RNA expression levels in normal prostate tissues were arbitrarily defined as 1.0. The data are presented as the mean $\pm S D$.

disease and progress to castration-resistant prostate cancer (CRPC). While CRPC patients with metastasis have therapeutic options for slowing cancer growth, metastatic CRPC remains lethal (16). Prostate cancer metastasis involves multiple steps, including angiogenesis, local migration, invasion, intravasation, circulation, extravasation, angiogenesis and colonization in distant sites (17). To facilitate the development of therapies targeting metastasisassociated molecules, it is imperative to determine which molecules are involved in the individual steps leading to bone metastasis. The observation that tumor-initiating cells with stem cell-like features and cells that have undergone epithelial-to-mesenchymal transition (EMT) can be found in CTCs indicates that CTCs may provide insight into molecules with the potential to address unmet needs in prostate cancer treatment. CTCs are likely to express various CAMs that mediate metastatic processes, such as vascularization, adherence to distant organs, extravasation, angiogenesis and proliferation. Therefore, this study focused on adhesion molecules expressed on the membrane of CTCs to identify and characterize factors that mediate metastasis. According to RNA-Seq analyses, Ninjurin1 was the most significantly up-regulated adhesion molecule expressed on CTC membranes compared with normal prostate epithelial cells. To date, several reports have demonstrated that Ninjurin1 may play an important role in cell motility. Bone marrow-derived macrophages depleted of Ninjurin1 exhibited a decrease in membrane protrusions and impaired cell motility. In Raw264.7 cells, overexpression of Ninjurin1 increased filopodial protrusion formation by activating 

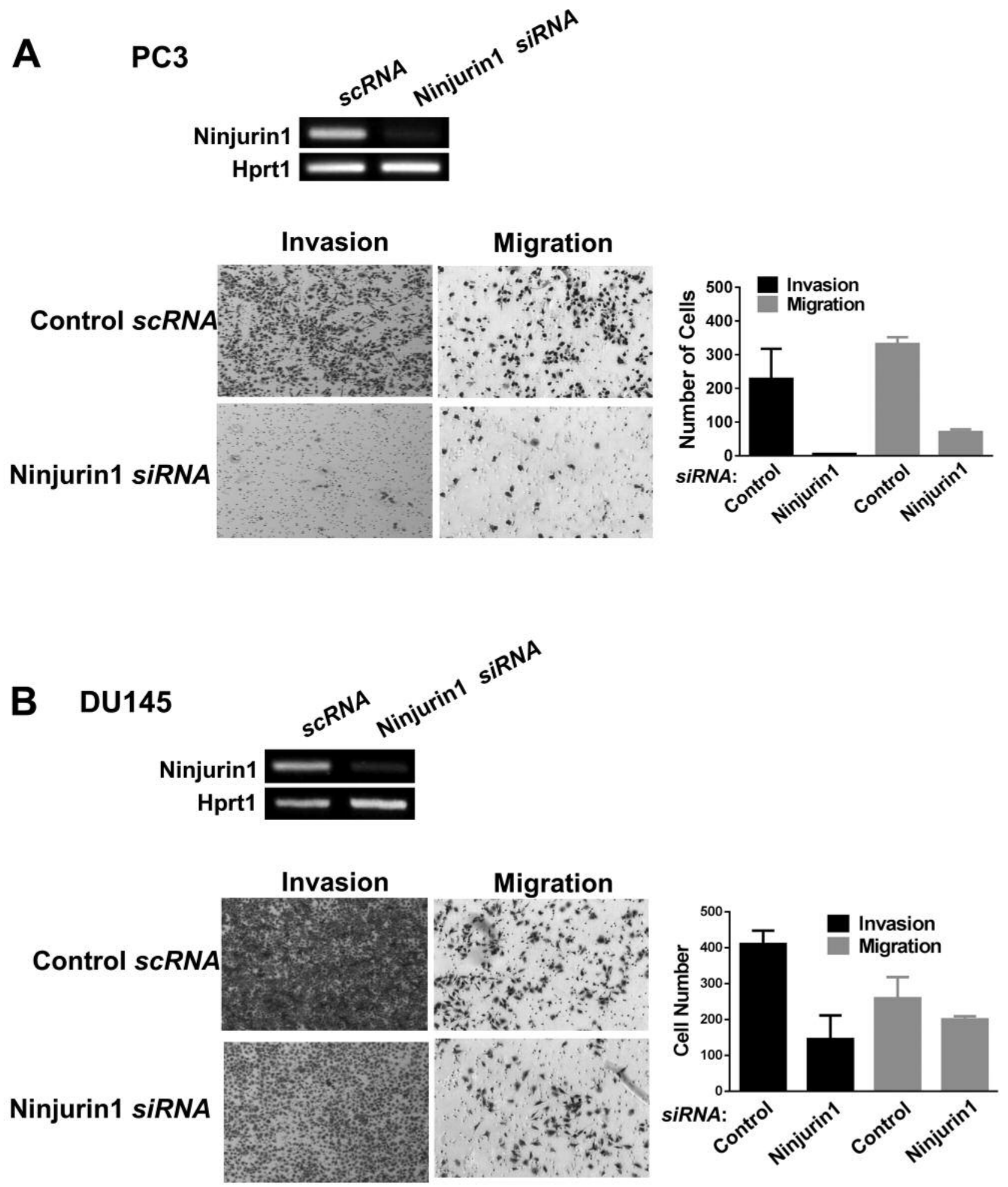

Figure 3. Down-regulation of Ninjurin1 transcripts reduces the migration of castration-resistant prostate cancer (CRPC) cells. siRNA targeting Ninjurin1 or control siRNA was transiently transfected into PC3 (A) or DU145 cells (B) and the effect of siRNA knockdown on Ninjurin1 expression was assessed using RT-PCR. The HPRT1 gene was used as a control. Cells $\left(1 \times 10^{5}\right)$ were transfected with siRNA for $48 \mathrm{~h}$ and then transferred to a membrane for the invasion and migration assays. After $48 \mathrm{~h}$, cells on the opposite side of the membrane were stained with hematoxylin and counted under a microscope. 


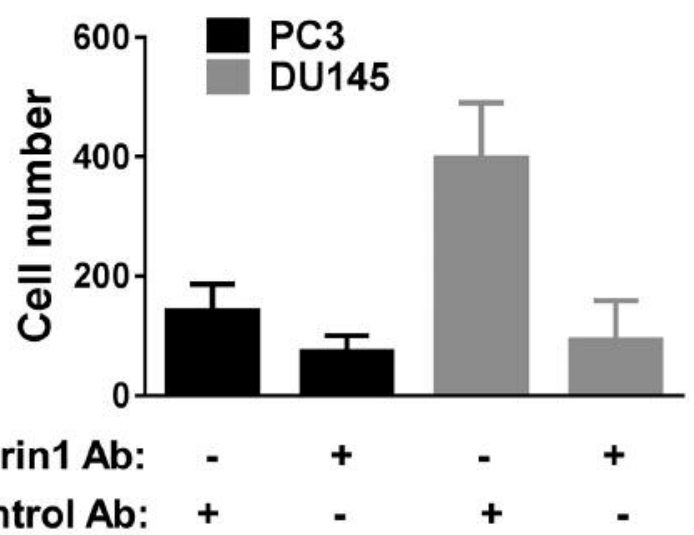

Figure 4. Blocking Ninjurin1 activity with a neutralizing antibody reduces the migration of metastatic castration-resistant prostate cancer (CRPC) cells. Metastatic CRPC cells were exposed to $500 \mathrm{ng}$ of a Ninjurin1 neutralizing antibody for $48 \mathrm{~h}$ and then transferred to a membrane for invasion and migration assays. Cells on the opposite side of the membrane were stained with hematoxylin and counted under a microscope.

Rac1, thereby promoting cell motility (18). Consistent with these findings, we found that blocking the homophilic interactions of membrane-bound Ninjurin1 in CRPC cells impaired invasion and migration, indicating that Ninjurin 1 may play a critical role in cancer cell invasion and migration in the blood.

The bone marrow (BM) is a common site of prostate cancer metastasis and the detection of tumor cells in the $\mathrm{BM}$ at the time of diagnosis is associated with an increased risk of tumor recurrence (19). In addition, a previous study detected more disseminated tumor cells in the BM compared to CTCs obtained from blood samples (20). The finding that disseminated tumor cells in the BM further disseminate to other sites suggests that the level of disseminated tumor cells in the BM may be a better diagnostic and prognostic biomarker in prostate cancer (15). However, this observation may be a consequence of the sensitivity of the assays used to detect CTCs. Recent technological advances have enabled the detection, isolation, capture and characterization of CTCs from blood samples obtained in routine clinical practice. The CellSearch system (Veridex LLC, Raritan, NJ, USA) established a protocol utilizing antibodies against epithelial cell adhesion molecule (EpCAM), a molecule that is commonly expressed on the majority of primary and metastatic tumor cells but that may be down-regulated or absent in a subset of CTCs. Similarly, cells with stem celllike features also lack EpCAM and cytokeratin expression. Thus, the identification of novel markers specifically expressed on CTCs that are not down-regulated during EMT may increase the potential for utilizing CTCs in the clinical setting. To overcome the limitations associated with the high level of sensitivity required to isolate CTCs, we developed a novel technology using a replicationcompetent adenovirus, Ad5/5E1aPSESE4, to label PSA/PSMA(+) cells (7). Interestingly, this adenovirusbased diagnostic tool provided similar results as conventional image-guided or PSA-based predictions of disease progression in most patients, although several patients with local tumors harbored too few CTCs in the blood to facilitate this type of analysis. These results suggest that CTC and disseminated tumor cells in the BM may have significant prognostic potential depending on the development of sensitive methods to detect CTCs.

Ninjurin1 is associated with cancer predisposition syndrome multiple self-healing squamous epitheliomata (21), a syndrome that renders patients vulnerable to multiple squamous cell skin cancers (22). With respect to hematological cancers, Ninjurin 1 expression is elevated in acute lymphocytic leukemia. In addition, Ninjurin 11 was identified by cDNA microarrays as a marker of B-lineage acute lymphoblastic leukemia (12). In solid cancers, Ninjurin1 was initially observed to be up-regulated in hepatocellular carcinoma associated with viral infection or liver cirrhosis (11). In non-muscle invasive bladder cancer, Ninjurin1 expression was associated with tumor progression, as demonstrated by immunohistochemical staining and tissue microarray (13). The cDNA microarray results demonstrated that Ninjurin 1 expression was associated with non-muscle invasive bladder cancer recurrence (23).

Of note, a microarray-based genetic screen revealed that the tumor suppressor protein p53 enhances Ninjurin1 expression; this finding has resulted in an increased interest in the potential role of Ninjurin1 in carcinogenesis (24). In prostate cancer, some studies have demonstrated an association between p53 nuclear accumulation and poor differentiation, disease progression, metastasis and androgenindependent growth (25-27). Ninjurin 1 expression appears to be regulated by p53 (28) and is associated with chemotherapy sensitivity.

In summary, Ninjurin1 expression was highly up-regulated in circulating tumor cells from some locally advanced prostate cancer and the inhibition of Ninjurin 1 expression or molecular action greatly reduced prostate cancer cell motility. Therefore, inhibiting Ninjurin1 homophilic interactions using Ninjurin1-neutralizing antibodies or inhibitory peptides or down-regulating Ninjurin1-expression using siRNA targeting Ninjurin1 may contribute to novel therapeutic approaches that can provide survival benefits to patients with metastatic potential.

\section{Conflicts of Interest}

The Authors declare no conflicts of interest. 


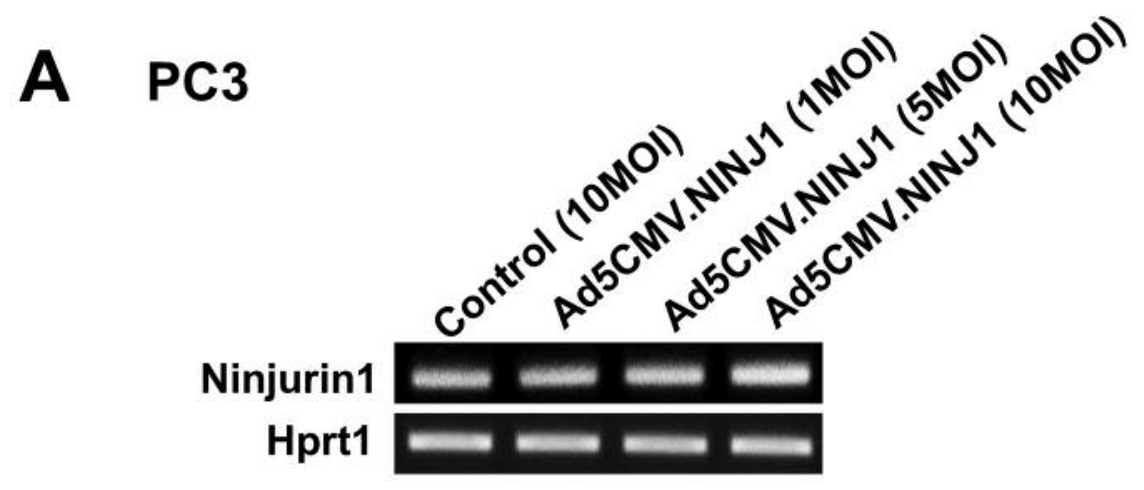

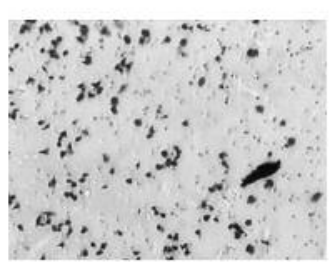

$10 \mathrm{MOI}$

$\overline{\text { Ad5MOCK }}$

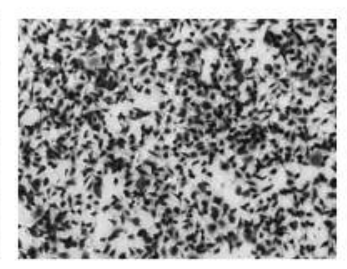

1 MOI

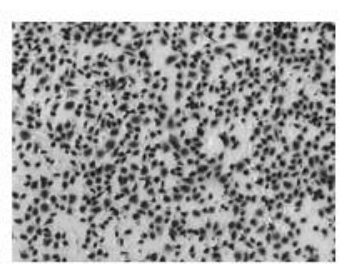

$10 \mathrm{MOI}$

Ad5CMV.NINJ1

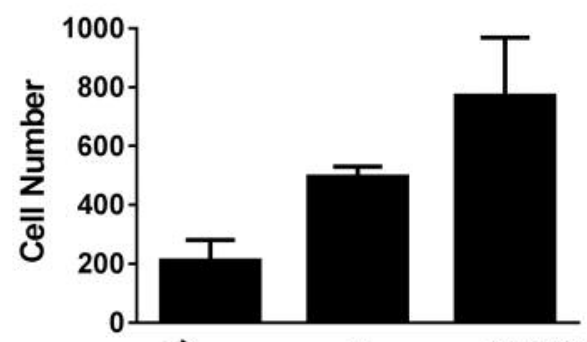

B DU145

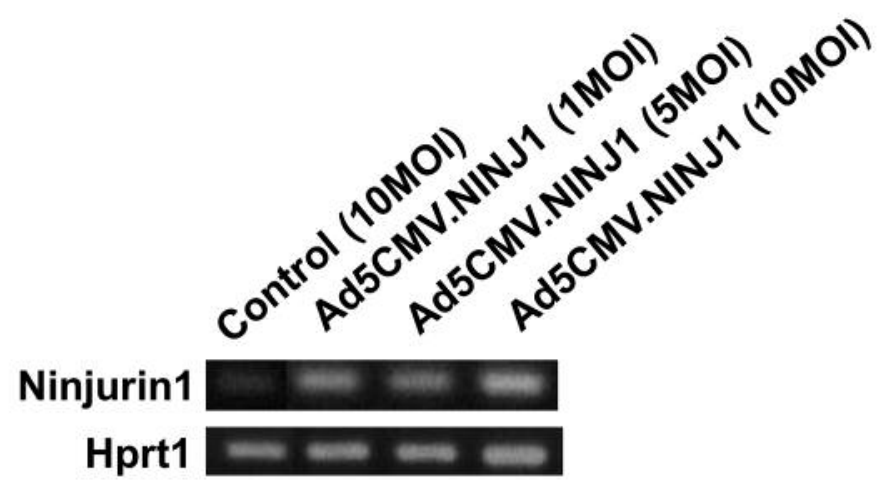

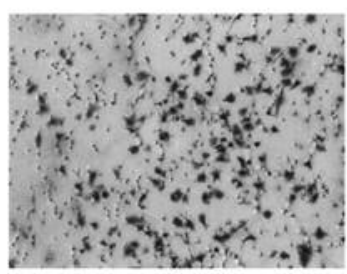

$\frac{10 \mathrm{MOI}}{\mathrm{Ad5MOCK}}$

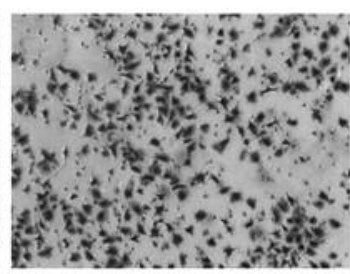

$1 \mathrm{MOI}$

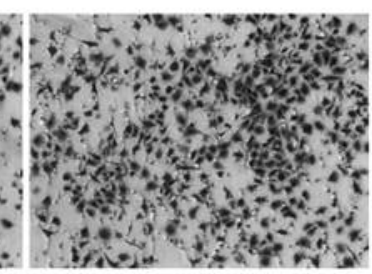

$10 \mathrm{MOI}$

Ad5CMV.NINJ1
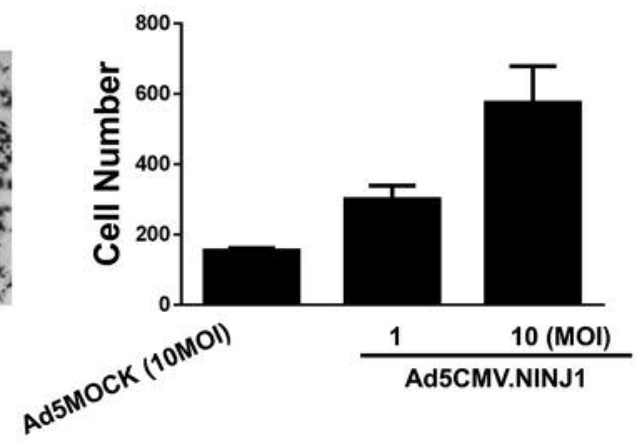

Figure 5. Overexpression of Ninjurin1 by adenovirus Ad5CMV.NINJ1 infection enhanced cell motility in metastatic prostate cancer cells. PC3 (A) or DU145 cells $\left(1 \times 10^{5}\right)(B)$ were infected with various doses of Ad5CMV.NINJ1 (VECTOR BIOLABS, Parkway, PA, USA). Forty-eight hours post infection, cells were transferred to a membrane for invasion and migration assays. Cells on the opposite side of the membrane were stained with hematoxylin and counted under a microscope. 


\section{Acknowledgements}

This study was supported by a grant from the National Cancer Center, Korea (NCC-1510170 and a grant from the Korean Urologic Oncology Society (KUOS 14-01). We would like to thank Mr. Seung-Phil Shin and Na-Rae Jung for supplying high-titered adenovirus.

\section{References}

1 Cancer IAfRo and Organization WH: GLOBOCAN: Estimated cancer incidence, mortality, and prevalence worldwide in 2012: IARC, 2014.

2 Yu M, Ting DT, Stott SL, Wittner BS, Ozsolak F, Paul S, Ciciliano JC, Smas ME, Winokur D, Gilman AJ, Ulman MJ, Xega K, Contino G, Alagesan B, Brannigan BW, Milos PM, Ryan DP, Sequist LV, Bardeesy N, Ramaswamy S, Toner M, Maheswaran S and Haber DA: RNA sequencing of pancreatic circulating tumour cells implicates WNT signalling in metastasis. Nature 487: 510-513, 2012.

3 Maheswaran S, Sequist LV, Nagrath S, Ulkus L, Brannigan B, Collura CV, Inserra E, Diederichs S, Iafrate AJ, Bell DW, Digumarthy S, Muzikansky A, Irimia D, Settleman J, Tompkins RG, Lynch TJ, Toner M and Haber DA: Detection of mutations in EGFR in circulating lung-cancer cells. N Engl J Med 359: 366-377, 2008.

4 Heitzer E, Auer M, Gasch C, Pichler M, Ulz P, Hoffmann EM, Lax S, Waldispuehl-Geigl J, Mauermann O, Lackner C, Hofler G, Eisner F, Sill H, Samonigg H, Pantel K, Riethdorf S, Bauernhofer T, Geigl JB and Speicher MR: Complex tumor genomes inferred from single circulating tumor cells by arrayCGH and next-generation sequencing. Cancer Res 73: 29652975, 2013

5 Ni X, Zhuo M, Su Z, Duan J, Gao Y, Wang Z, Zong C, Bai H, Chapman AR, Zhao J, Xu L, An T, Ma Q, Wang Y, Wu M, Sun Y, Wang S, Li Z, Yang X, Yong J, Su XD, Lu Y, Bai F, Xie XS and Wang J: Reproducible copy number variation patterns among single circulating tumor cells of lung cancer patients. Proc Natl Acad Sci USA 110: 21083-21088, 2013.

6 Lohr JG, Adalsteinsson VA, Cibulskis K, Choudhury AD, Rosenberg M, Cruz-Gordillo P, Francis JM, Zhang CZ, Shalek AK, Satija R, Trombetta JJ, Lu D, Tallapragada N, Tahirova N, Kim S, Blumenstiel B, Sougnez C, Lowe A, Wong B, Auclair D, Van Allen EM, Nakabayashi M, Lis RT, Lee GS, Li T, Chabot MS, Ly A, Taplin ME, Clancy TE, Loda M, Regev A, Meyerson M, Hahn WC, Kantoff PW, Golub TR, Getz G, Boehm JS and Love JC: Whole-exome sequencing of circulating tumor cells provides a window into metastatic prostate cancer. Nat Biotechnol 32: 479-484, 2014.

7 Hwang JE, Joung JY, Shin SP, Choi MK, Kim JE, Kim YH, Park WS, Lee SJ and Lee KH: Ad5/35E1aPSESE4: A novel approach to marking circulating prostate tumor cells with a replication competent adenovirus controlled by PSA/PSMA transcription regulatory elements. Cancer Lett 372(1): 57-64, 2015.

8 Araki T and Milbrandt J: Ninjurin, a novel adhesion molecule, is induced by nerve injury and promotes axonal growth. Neuron 17: 353-361, 1996.

9 Ifergan I, Kebir H, Terouz S, Alvarez JI, Lecuyer MA, Gendron S, Bourbonniere L, Dunay IR, Bouthillier A, Moumdjian R,
Fontana A, Haqqani A, Klopstein A, Prinz M, Lopez-Vales R, Birchler T and Prat A: Role of Ninjurin-1 in the migration of myeloid cells to central nervous system inflammatory lesions. Ann Neurol 70: 751-763, 2011.

10 Odoardi F, Sie C, Streyl K, Ulaganathan VK, Schlager C, Lodygin D, Heckelsmiller K, Nietfeld W, Ellwart J, Klinkert WE, Lottaz C, Nosov M, Brinkmann V, Spang R, Lehrach H, Vingron M, Wekerle H, Flugel-Koch $\mathrm{C}$ and Flugel A: T cells become licensed in the lung to enter the central nervous system. Nature 488: 675-679, 2012.

11 Kim JW, Moon AR, Kim JH, Yoon SY, Oh GT, Choe YK and Choe IS: Up-Regulation of ninjurin expression in human hepatocellular carcinoma associated with cirrhosis and chronic viral hepatitis. Mol Cells 11: 151-157, 2001.

12 Chen JS, Coustan-Smith E, Suzuki T, Neale GA, Mihara K, Pui $\mathrm{CH}$ and Campana D: Identification of novel markers for monitoring minimal residual disease in acute lymphoblastic leukemia. Blood 97: 2115-2120, 2001.

13 Mhawech-Fauceglia P, Ali L, Cheney RT, Groth J and Herrmann FR: Prognostic significance of neuron-associated protein expression in non-muscle-invasive urothelial bladder cancer. $\mathbf{J}$ Clin Pathol 62: 710-714, 2009.

14 Gene Ontology C: Gene Ontology Consortium: Going forward. Nucleic Acids Res 43: D1049-1056, 2015.

15 Danila DC, Heller G, Gignac GA, Gonzalez-Espinoza R, Anand A, Tanaka E, Lilja H, Schwartz L, Larson S, Fleisher M and Scher HI: Circulating tumor cell number and prognosis in progressive castration-resistant prostate cancer. Clin Cancer Res 13: 7053-7058, 2007.

16 Coleman RE: Clinical features of metastatic bone disease and risk of skeletal morbidity. Clin Cancer Res 12: 6243s-6249s, 2006.

17 Jin JK, Dayyani F and Gallick GE: Steps in prostate cancer progression that lead to bone metastasis. Int J Cancer 128: 25452561, 2011.

18 Ahn BJ, Le H, Shin MW, Bae SJ, Lee EJ, Wee HJ, Cha JH, Lee HJ, Lee HS, Kim JH, Kim CY, Seo JH, Lo EH, Jeon S, Lee MN, Oh GT, Yin GN, Ryu JK, Suh JK and Kim KW: Ninjurin1 deficiency attenuates susceptibility of experimental autoimmune encephalomyelitis in mice. J Biol Chem 289: 3328-3338, 2014.

19 Kollermann J, Weikert S, Schostak M, Kempkensteffen C, Kleinschmidt K, Rau T and Pantel K: Prognostic significance of disseminated tumor cells in the bone marrow of prostate cancer patients treated with neoadjuvant hormone treatment. J Clin Oncol 26: 4928-4933, 2008.

20 Pantel K, Alix-Panabieres $\mathrm{C}$ and Riethdorf S: Cancer micrometastases. Nat Rev Clin Oncol 6: 339-351, 2009.

21 Chadwick BP, Heath SK, Williamson J, Obermayr F, Patel L, Sheer D and Frischauf AM: The human homologue of the ninjurin gene maps to the candidate region of hereditary sensory neuropathy type I (HSNI). Genomics 47: 58-63, 1998.

22 Goudie DR, Yuille MA, Leversha MA, Furlong RA, Carter NP, Lush MJ, Affara NA and Ferguson-Smith MA: Multiple selfhealing squamous epitheliomata (ESS1) mapped to chromosome 9q22-q31 in families with common ancestry. Nat Genetics 3: 165-169, 1993.

23 Mares J, Szakacsova M, Soukup V, Duskova J, Horinek A and Babjuk M: Prediction of recurrence in low and intermediate risk non-muscle invasive bladder cancer by real-time quantitative PCR analysis: cDNA microarray results. Neoplasma 60: 295$301,2013$. 
24 Kannan S, Sutphin RM, Hall MG, Golfman LS, Fang W, Nolo RM, Akers LJ, Hammitt RA, McMurray JS, Kornblau SM, Melnick AM, Figueroa ME and Zweidler-McKay PA: Notch activation inhibits AML growth and survival: A potential therapeutic approach. J Exp Med 210: 321-337, 2013.

25 Navone NM, Troncoso P, Pisters LL, Goodrow TL, Palmer JL, Nichols WW, von Eschenbach AC and Conti CJ: p53 protein accumulation and gene mutation in the progression of human prostate carcinoma. J Natl Cancer Inst 85: 1657-1669, 1993.

26 Bookstein R, MacGrogan D, Hilsenbeck SG, Sharkey F and Allred DC: p53 is mutated in a subset of advanced-stage prostate cancers. Cancer Res 53: 3369-3373, 1993.
27 Eastham JA, Hall SJ, Sehgal I, Wang J, Timme TL, Yang G, Connell-Crowley L, Elledge SJ, Zhang WW, Harper JW and Timothy C: In vivo gene therapy with $\mathrm{p} 53$ or $\mathrm{p} 21$ adenovirus for prostate cancer. Cancer Res 55: 5151-5155, 1995.

28 Cho SJ, Rossi A, Jung YS, Yan W, Liu G, Zhang J, Zhang M and Chen X: Ninjurin1, a target of p53, regulates p53 expression and p53-dependent cell survival, senescence, and radiation-induced mortality. Proc Natl Acad Sci USA 110: 9362-9367, 2013.

Received February 7, 2017

Revised March 7, 2017

Accepted March 8, 2017 